\title{
DE MITOS, LEYENDAS Y CUENTOS: NECESIDAD DIDÁCTICA DEL GÉNERO NARRATIVO
}

\author{
Amando López Valero \\ Eduardo Encabo Fernández \\ Universidad de Murcia
}

\begin{abstract}
RESUMEN. El propósito del trabajo que aquí presentamos es el de propugnar la recuperación del trabajo con el género narrativo dentro de las instituciones educativas. A través de sus diferentes modalidades, mitos, leyendas o cuentos, queremos expresar que es posible concebir una enseñanza que contemple esta modalidad literaria con el fin último de recuperar la fantasía y la imaginación de las personas.

Además, queremos proporcionar algunas pautas de actuación dentro de una filosofía de enseñanza de la Lengua y la Literatura que deben de servir para impulsar la transformación educativa y social, deseada por nosotros.

ABSTRACT. The aim of this work here presented is to defend the recovery of the narrative gender work inside the educational institutions. Through its different modalities, myths, legends or tales, we want to express that it is possible understand a teaching model that includes this literary modality with the final objective of recover the imagination and the fantasy of people.

Furthermore, we want to provide some patterns of performance inside of a teaching of the Language and the Literature philosophy that should help to get the social and educative changing that we wish.
\end{abstract}

\section{Introducción}

Es nuestro deseo iniciar este texto haciendo alusión al título que lo encabeza, sin duda que pensar en la antigüedad de los términos que en él se encuentran puede provocar un estado hirsuto de los cabellos de la persona lectora. Efectivamente, el origen de las narraciones -para el caso orales- se remonta hasta tiempos remotos, con lo que podemos decir que esta actividad asociada al uso del lenguaje se puede asimilar e incluso solapar al progreso de la humanidad. Tras esta digresión que implícitamente aclara el interés de nuestra aportación, debemos decir que este trabajo se rige por las directrices de la necesidad de trabajar de forma didáctica con este tipo de género. Hemos de ser conscientes de que, en la sociedad actual en la cual vivimos, es complicado generar procesos de atracción por los cuentos -sobre todo en las edades correspondientes a la pubertad y a la adolescencia-, pero ello no es óbice para reconocer la importancia que puede tener este tipo de género literario en la formación, tanto cognitiva como afectivosocial, de las personas. A lo largo del texto, veremos la ubicación de lo narrativo 
dentro del ámbito de las Ciencias Sociales, cómo lo mecánico y racional han inhibido los procesos relacionados con la fantasía y la imaginación, la necesidad de potenciar la función poética del lenguaje y por último qué uso tienen las distintas modalidades del género narrativo en las aulas de las instituciones educativas.

Por lo apuntado anteriormente, queremos incardinar la didáctica del género narrativo en el área de conocimiento que supone la Didáctica de la Lengua y la Literatura. Como disciplina científica específica, desde ella serán elaboradas las pautas, los diseños y aplicaciones que sirvan de vehículo para que la labor con las narraciones sea realmente lúdica, y sobre todo, educativa. Veamos pues, en qué situación se halla la Didáctica de la Lengua y la Literatura en los albores de este siglo XXI que nos acontece.

\section{Sísifo y la Didáctica de la Lengua y la Literatura}

Nuestra área de conocimiento se halla en un impás temporal complicado de solucionar. Podríamos decir que es víctima de una importante contradicción, por una parte se demanda de forma vehemente que se potencie la enseñanza de la Lengua y la Literatura, pero -de un modo paralelo- se prescinde de todo el espectro de posibilidades que los usos lingüístico-comunicativos pueden ofrecer a las personas. La imposición de lo holofrástico, del uso de anacolutos u otras modalidades de reducción de la comunicación entre las personas, producen una importante desazón entre quienes nos dedicamos a investigar en esta área de conocimiento. Por tanto, es lógico que sintamos un cierto sentimiento empático con el Rey de Corinto cuando este veía caer de nuevo su piedra al llegar a la cúspide de la montaña. Y es normal que lo hagamos porque los progresos que se puedan hacer en las instituciones educativas se diluyen por la inercia social de un sistema basado en la producción y en la "eficacia"; en el mismo, tiene cabida la denominada economía del lenguaje, con lo cual, indefectiblemente, las restricciones cada vez se hacen más patentes.

Lo previamente expresado no atiende a un alegato anti-progreso sino que pretende poner de manifiesto la situación de indefensión y oscurantismo que sufre todo lo relacionado con lo lingüístico-comunicativo. Es más, nuestro enfoque docente e investigador aboga por una enseñanza de la Lengua y la Literatura contextualizada y que por encima de todo, prepare a las nuevas generaciones para efectuar la transición hacia el mundo social sin ningún tipo de dificultad (Beaufort, 1999). Nuestras diatribas se dirigen hacia la indolencia del profesorado, madres y padres u otros agentes implicados en la labor de hacer adquirir o perfeccionar la competencia comunicativa que pueda poseer una persona.

Desde la Didáctica de la Lengua y la Literatura debemos defender un enfoque comunicativo-funcional que propugne unos procesos de enseñanza y aprendizaje basados en la construcción conjunta de lo que los hechos lingüístico-comunicativos significan para todas las personas presentes en la educación (López y Encabo, 2001a). De nada sirve reproducir las estructuras lingüísticas ya dadas, eso lo único que provoca es el favorecimiento de la progresiva pérdida de la identidad lingüística. Y lo hace en virtud de que no fomenta en las personas que aprenden el espíritu investigador, el sapere aude kantiano, la avidez de conocimiento, propiciando de ese modo el anquilosamiento y progresiva pérdida de la calidad en los procesos comunicativos. Por ese motivo, debemos de intentar colocar las condiciones adecuadas para favore- 
cer que las personas hagan un buen uso del lenguaje, que trabajen con las palabras y que conformen discursos que a la vez posean cohesión, y ante todo, coherencia (López y Encabo, 2001b). Gran parte de culpa de que las personas se hayan despreocupado por su trato por el lenguaje lo achacamos a la falta de originalidad, al progresivo desvanecimiento de la imaginación. Observemos a continuación cómo las condiciones sociales propician la no presencia de la fantasía dentro del entramado de funcionamiento que nos rige.

\section{Virgilio y el viaje a los infiernos de la imaginación}

No ha lugar a la discusión, vivimos en una sociedad con un acento marcadamente económico y, sobre todo, productivo. Con esta premisa queda casi todo dicho, imaginar es divagar y por tanto dejar que el tiempo transcurra. Imaginar es alejarse de la realidad y ubicarse en otras coordenadas espacio-temporales, lo cual implica una pérdida de producción material. Esto es impensable en los tiempos que nos contemplan, ya que supone quedar atrás en la carrera de la meritocracia. No es nuestro antojo el ejercer de Virgilio y -representando a la razónmostrar a las personas cómo la imaginación ha iniciado un viaje, de momento sin retorno, a los infiernos. Y es que, a corto y medio plazo temporal, no se atisba indicio alguno de recuperación.

Un elemento importante en la erradicación de la imaginación de los ámbitos sociales, y sobre todo, del educativo, supone la presentación del conocimiento, de los saberes, separados de las emociones e intenciones humanas. Con ello, se reduce su significado afectivo, y paulatinamente va configurando el pensamiento de las personas como algo de naturaleza mecánica, sin que la opción de soñar o de idear sea algo tangible. En términos saussurianos diríamos que se pone casi todo el énfasis en el significante, dejando en un segundo plano al significado. Con referencia a este segundo componente, debemos decir que no se olvida su función, pero se procura omitir la polisemia, induciendo de ese modo a que la hermenéutica sea algo unívoco, un pensamiento único que albergue toda la razón, creándose de ese modo cadenas de producción, que a fin de cuentas es lo que se busca.

Todo este planteamiento afecta a la Didáctica de la Lengua y la Literatura en la medida de la formación del profesorado de Lengua y Literatura y en la selección de contenidos y métodos que se deben aplicar para su enseñanza. Desde nuestra perspectiva, debemos ser beligerantes con la preparación de las y los docentes para que sirvan de contrapunto a la desaforada explosión neoliberal en la cual vivimos (López y Encabo, 2000a). Tenemos que orientar nuestra labor al pensamiento de que el significado es lo que realmente tiene trascendencia y relevancia en el quehacer cotidiano de las personas. Por esa razón, hay que adherirse a la opinión basada en que el pensamiento del alumnado no es una tabula rassam, que no se aprenden muchos de los conceptos porque ya se dispone de ellos cuando se llega a las instituciones educativas. Simplemente se utilizan para aprender aspectos del mundo y de la experiencia (Egan 1994). Se impone pues, un cambio de enfoque hacia esa funcionalidad que ya hemos apuntado. Importante será ese aspecto del lenguaje presente en los procesos comunicativos al cual denominamos función poética, recuperar su importancia, y reforzar el trabajo con la misma pueden ser claves para restituir el lugar social de la palabra y para poder aproximarnos a la labor didáctica con lo narrativo con mejores herramientas (López y Encabo, 2000b). 


\section{Prometeo y la recuperación de lo poético}

Tras considerar el desarrollo político-económico de la sociedad como una apología del dislate con respecto a las repercusiones que pueda tener sobre el desarrollo afectivo-social de las personas, por reductio ad absurdum podemos inferir que se impone una solución para paliar la denunciada situación. En el esquema comunicativo clásico aportado por Jakobson (1984) hallamos que la función poética del lenguaje es la que se refiere al mensaje que la persona emisora pretende transmitir a la receptora. Ese mensaje está compuesto por signos, entre los que se incluyen en una progresión ascendente las letras, los fonemas, los morfemas y el contenido. Pues bien, al parecer, el sistema neoliberal está royendo esos signos de forma descendente. Parece que el contenido ya ha sido engullido; ahora es labor de los didactas el recuperarlo. Esa apuntada función poética debe afectar al mensaje en lo que concierne, primero a su semántica y estructura, y posteriormente en lo que respecta a su estética (los mecanismos metalingüísticos que afectarán al código). La situación actual no se puede catalogar de patética pero casi, ya que la cohesión falla, es decir la transcripción escrita y hablada de los códigos es en muchas ocasiones errónea, por no hablar de los aspectos semánticos. Esto implica que ni por asomo podamos acercarnos al valor estético que es posible conferir al lenguaje.

Enlazando con el segundo de los apartados de este escrito, hemos de decir que la transformación de la enseñanza hacia esa apuntada función poética, pasa ineluctablemente por la transición hacia procesos de creación lingüística. De nada sirve mantener las estructuras tradicionales que simplemente hacen que el alumnado recepcione contenidos que pasan a almacenarse en la memoria a corto plazo, pero que no tienen significación alguna para esas personas. Precisamos que la enseñanza pase a ser algo contextualizado, con contenidos funcionales, que tenga en cuenta los conocimientos previos del alumnado y propicie una actuación que conduzca a la elaboración de esquemas de conocimiento por parte del mismo (Mendoza, López y Martos, 1996). En definitiva, que sean las personas las que se vayan apropiando del lenguaje, que lo hagan suyo, para así poder utilizarlo de forma apropiada y en su propio beneficio en diferentes contextos y situaciones. Para ello, es fundamental el uso de la fantasía y la imaginación, como nos dice Rodari (1991), éstas no deben quedar en el ámbito de lo abstracto y de lo filosófico sino que deben entrar de lleno en las aulas de Lengua y Literatura. Tenemos que obrar como Prometeo e intentar robar el control de la influencia, para conseguir que la gente deje de estar alienada y pueda aproximarse a lo fantasioso y a lo imaginario.

Pasemos a observar cómo se aplica todo lo expuesto en estos tres apartados para la didáctica del género narrativo. Veremos que estos presupuestos son fundamentales para propiciar la pretendida actividad educativa.

\section{Orfeo y la didáctica del género narrativo}

Hablar del género narrativo dentro de un contexto educativo supone tener que englobarlo forzosamente en la Literatura Infantil y Juvenil. Este tipo de Literatura se caracteriza por estar dirigida a personas que se hallan en edad evolutiva (Nobile, 1992), es decir que podríamos cifrar ese intersticio temporal entre los cuatro o cinco años y los quince o dieciséis. Esta podría ser la franja de edad en la que la narración sería susceptible de tener un valor didáctico que repercutiese en la formación de las 
personas. Evidentemente, tal y como nos indica Sánchez (1995a), la Literatura Infantil y Juvenil posee un ideal propedéutico que está cimentado en la construcción del yo en y por el discurso. Quiere decirse pues que a través de la misma tratamos de aproximarnos a la noción del ideal lingüístico-comunicativo. Y es que a través de la comunicación literaria se trata de iniciar a las nuevas generaciones en el diálogo cultural establecido en cualquier tipo de sociedad (Colomer, 1999).

Obviamente, la narración debe servir de puente entre la cultura y la persona, pero tenemos que evitar -a través de la fantasía y de la imaginación- caer en la mecanización. Optar por jugar con los textos, con las palabras, significa penetrar en ellas, recrear situaciones vitales en las que de forma concreta el lenguaje luce su poder expresivo y las imágenes literarias se realizan (Cervera, 1991). El objetivo final es que las personas se apoderen paralelamente del lenguaje cotidiano y del lenguaje de tipo literario, este último "crea un mundo propio, un mundo de ficción que se rige por sus propias leyes y que está totalmente diferenciado del mundo real, por muy realistas que parezcan sus contenidos" (Sotomayor, 2000: 28). Podríamos haber optado por cualquiera de los otros géneros literarios, bien poesía o teatro, pero creemos que por su tradición e importancia el cuento puede conducirnos perfectamente hacia la mejora de la comunicación entre las personas. Además, como nos sugiere Todorov (1988), los géneros literarios tienen su origen, lisa y llanamente en el discurso humano. Es nuestro propósito el recuperar la narrativa como hizo Orfeo con Eurídice, para vehiculizar las actuaciones didácticas. Comencemos por ver la evolución de este género, expresando qué entendemos por mito y cómo éste se halla presente en muchas de las partes de los cuentos.

\subsection{Mito}

Sin ningún tipo de vacilación podemos decir que esta desvelación prerracional del mundo se ha convertido en un andamio fundamental para el avance del conocimiento humano. El mito es una realidad cultural extremadamente compleja y la primera manifestación de una cosa que es significativa y válida (Eliade, 1973). A través de él se trata de intentar conferir una significación a la vida humana dentro de los parámetros de realidad, verdad y significación. Mediante los mitos, el ser humano se eleva más allá de su cautiverio en lo ordinario, adquiere poderosas visiones del futuro y se hace consciente de ellas. El mito, en definitiva, es dar un significado y un sentido a la vida. Nos dice May (1998) que sin el mito somos como una raza de disminuidos mentales, incapaces de ir más allá de la palabra y de escuchar a la persona que habla.

Parafraseando a Tejero (1997), en el principio fueron los rayos y los truenos, las luces y las tinieblas, el agua y el fuego; posteriormente, apareció la onomatopeya y luego... el mito como la personificación de lo natural para alivio de los primeros temores. El mito pues, no es una explicación que satisfaga un interés científico sino de resurrección narrativa de una necesidad primitiva, contada para satisfacer profundas necesidades religiosas y ansias morales. En los mitos hallamos la base de las alegorías y emblemas ingeniosos, además de un vehículo para la moralización. Es sin duda la creación de nuevo lenguaje figurativo y un tipo distinto de Literatura (Moormann y Uitterhoeve, 1997).

Si echamos un vistazo a los epígrafes que componen los apartados de esta aportación, observaremos que han sido confeccionados a partir de famosos mitos, que tie- 
nen la suficiente vigencia como para ser aplicados y en absoluto desentonar; y es que, como nos indica Parkin (1998), un gran número de especialistas en antropología, apuntan al simbolismo como la característica humana fundamental. La diferencia clave entre el mito y la leyenda -que en el siguiente subapartado procedemos a definir- reside en su localización en regiones y tiempos fuera del alcance humano, y la presencia en los mismos de personajes divinos.

\subsection{Leyenda}

A diferencia del mito -y como más adelante veremos del cuento- en la leyenda hallamos una descripción geográfica pormenorizada, además de una precisa aportación sobre las características que poseen los personajes que se convierten en los protagonistas de la trama (Van Gennep, 1982). Puede suceder confundir el mito con la leyenda, pero realmente es que el primero es una leyendo sólo que con las características específicas que en el anterior subapartado ya hemos señalado. Por tanto, podemos decir que la leyenda tiene un matiz más real, menos abstracto que el mito. Igualmente se ubica en la memoria colectiva que un pueblo o país pueda tener. Martos (1988) apunta a la contextualización como elemento distintivo, ya que se constituye en un mecanismo de adaptación de las narraciones a los diversos entornos culturales en que van siendo reelaboradas. Podemos decir que la leyenda se sitúa a caballo entre el mito y el cuento, siendo la frontera entre los tres un fino hilo que apenas permite observarla, con lo que es lógico y normal que a veces se tienda a la confusión entre ellos, pero si nos atenemos a los aspectos relacionados con las coordenadas espacio-temporales y con la descripción de los personajes, se nos facilitará la labor de identificación. Veamos a continuación qué entendemos por el cuento, sin duda alguna la modalidad más extendida del género narrativo.

\subsection{Cuento}

Cuando nos aproximamos a la definición de cuento, si es nuestra intención el hacerla sencilla pero un tanto ambigua, diremos que es un relato de cierta longitud que conlleva una sucesión de motivos o episodios. Pero si hablamos del cuento debemos aproximarnos a una mayor exhaustividad. Los cuentos albergan en su interior una gran variedad de enseñanza que es preciso tener en cuenta y, sobre todo, aprovechar. Numerosas son esas aportaciones, a modo de ejemplo podríamos indicar el compartir, el hacerse valer, el perdón, la paciencia... en definitiva, valores de naturaleza humana que es conveniente y pertinente transmitir (Rowshan, 1999). Por tal razón, deseamos ir un poco más allá y retomar otra definición que explicite lo dicho. El cuento será pues, una creación de índole literaria, de naturaleza oral o escrita, en la cual serán relatadas vivencias, fantasías, experiencias etc., es decir, se podrá hacer una aproximación tanto a lo fantástico como a lo real, de una forma intencionalmente artística, con la finalidad última de divertir y de enseñar (Trigo y otros, 1995).

Como ya hemos indicado la práctica de la narración, se ha venido desarrollando desde tiempos pretéritos, y suponemos que lo seguirá haciendo con el transcurso de los años que se sucederán. Hay que decir que la narración de historias (cuento) es un medio poderoso. Una historia bien narrada puede inspirar acción, fomentar la comprensión de experiencias culturales, expandir el conocimiento del niño o de la niña o, también, proporcionar diversión (Raines e Isbell, 2000). Además, el tiempo del cuento es el tiempo del juego. En ambos espacios temporales, el niño o la niña, como 
referentes más clásicos o la persona, en general vive una experiencia de entusiasmo y se divierte, porque la inmersión en el relato supone construir un espacio simbólico, que en ocasiones le alejará de sus temores (Sánchez, 1995b). Como dimana de lo dicho, vemos la presencia de lo simbólico, del halo mítico que se encuentra en el cuento. Con respecto a la estructura más prototípica, decir que los elementos constantes de un cuento son las funciones de sus personajes y que la sucesión de esas funciones es siempre idéntica. Esto sucede tanto en los cuentos de costumbres, como en los cuentos de animales o en los cuentos maravillosos, con la salvedad de que en estos últimos el número de funciones de los personajes es limitado (Propp, 1977).

Una vez que nos hemos acercado a las nociones de mito, de leyenda o del cuento, veamos en el siguiente de los subpartados cuáles serían algunas de las indicaciones para el trabajo didáctico con el género narrativo en las aulas de las instituciones educativas.

\subsection{Su aplicación en las aulas}

Antes de comenzar este apartado, es preciso aclarar que somos reticentes a incluir la novela como modalidad habitual dentro del trabajo con Literatura Infantil y Juvenil. Si bien es cierto que puede ser muy útil, sólo lo será cuando el trabajo se realice con las y los estudiantes de mayor madurez. Entonces sí que podremos recurrir a la novela histórica o bien a la literatura amarilla, la novela de terror o novelas rosas, pero si nuestra intención es la de recuperar la calidad de los procesos comunicativos en un sector de población que principalmente va a oscilar aproximadamente entre los cinco y los quince años, debemos dejar un poco de lado la novela y centrarnos en las restantes modalidades, principalmente en el relato o cuento.

Los objetivos principales que nos debemos de marcar con la utilización de la narración en las aulas los constituyen principalmente la adquisición de vocabulario, el desarrollo de la competencia literaria, la motivación, el estímulo y desarrollo de la imaginación y, sobre todo, el intercambio comunicativo. Como nos dicen Zaro y Salaberri (1993), la Literatura, en sus diferentes manifestaciones debe sugerir y estimular la imaginación, activar la motivación y enriquecer y hacer significativos los contextos en los cuales se desenvuelve la persona. Se trata de hacer que esta última crezca tanto intelectual como moralmente con el trabajo realizado y generado a través de las narraciones (Obiols, 1998; Conesa, 2000). A partir de estas asunciones debemos decir que el cuento nos ofrece un variado espectro de posibilidades para que sea desarrollado el trabajo con el mismo. Alternativas surgen con facilidad, clásicos son el cambio de género de los protagonistas, la modificación de las características de los mismos, los cambios de escenarios... Otras opciones las hallamos, como nos dice López (1995) en el juego con los nombres de las personas, es decir referirnos a lo más sencillo, elaborar una narración. También es posible crear un texto narrativo a partir de lo gráfico, es decir, de fotografías, de recortes o bien hacer entrevistas a los personajes del mismo, trabajar el ritmo y la entonación... En definitiva, un inmenso elenco de opciones que se situarían a disposición de las personas educadoras para que ellas discerniesen si les son útiles y sobre los espacios y los tiempos en los cuales hacer uso de las mismas.

\section{Belerofonte y las perspectivas futuras}

Como si se nos hubiera concedido un caballo volador transfigurado en la imaginación y las ganas de transformar la realidad educativa y social, debemos de intentar 
vencer a lo mecánico, en definitiva, al sopor y al tedio que nos asolan en este comienzo del Tercer Milenio. Sólo de esa manera podremos afrontar la desoladora realidad lingüístico-comunicativa con la cual tenemos que cohabitar. Lo cierto es que la lectura y la escritura se han convertido en seria dificultad para poder desarrollar adecuados procesos de formación en las personas. Por eso, desde nuestra óptica queremos trabajar para que la lectura y la escritura no se deslinden, y para que las repercusiones que tenga nuestro trabajo sean igual de productivas para ambas (Heller, 1999). Pensamos que el trabajo con la creación literaria, además de recuperar la fantasía y la imaginación, va a incidir en el desarrollo de ciertas capacidades por parte de la persona que aprende. Así, por ejemplo, como nos dice Clement (2001) se favorecerá la capacidad para entender lo que representa la escritura, la valoración y comprensión de las formas de lectura, y algo que alcanza gran trascendencia, la motivación por el aprendizaje.

Con un enfoque eminentemente orientado al desarrollo de las comunidades de aprendizaje sin que exista lugar a la discriminación (Encabo, 2000) tratamos de diseñar planes de actuación que a través del trabajo de creación fomenten el acceso a la mejora de la lectura y de la escritura, aparte de las otras dos habilidades lingüísticas básicas como son el habla y la escucha. Una vez logradas nuestras aspiraciones de la mejora de lo lingüístico-comunicativo, se puede dar un paso hacia adelante y fomentar en la persona la competencia comunicativa, entendida como aquello que precisa para entender y producir textos con un carácter estético y literario, a ser posible adornando esta competencia con un tinte axiológico, introduciendo la labor con los valores en nuestra tarea educativa (López y Encabo, 2000c). Dentro de este tipo de competencia, podemos hablar de una subcompetencia que se hallaría muy en relación con la temática que venimos abordando a lo largo de todo el texto, la cual sería la competencia narrativa, que se constituiría en el objetivo último del trabajo con el género narrativo, es decir, saber contar historias a la vez que saber escribirlas, poniendo en juego la escritura y la oralidad.

Como colofón a este texto debemos aludir nuevamente al mundo desenfrenado en el cual habitamos, al proceso de homogeneización que sufrimos. Pensamos que ésta no es buena nada más que para unos pocos, ya que el resto de personas sufren. Debemos recordar que somos personas, con valores y sentimientos, no somos autómatas que ni sienten ni padecen (López y Encabo, 2000d). Por esas razones, debemos intentar derrotar a la quimera neoliberalismo, y devolver al primer plano protagonista a la fantasía y a la imaginación, con la finalidad de restablecer el equilibrio entre lo imaginario y lo racional.

\section{Referencias bibliográficas}

BEAUFORT, A. (1999). Writing in the real world. Making the transition from school to work. Londres: Teachers College Press.

CERVERA, J. (1991). Teoría de la Literatura Infantil. Bilbao: Mensajero.

CLEMENT, M. (2001). Enseñar a leer. Madrid: Pirámide.

COLOMER, T. (1999). Introducción a la Literatura Infantil y Juvenil. Madrid: Síntesís.

CONESA, M. A. (2000). Crecer con los cuentos. Bilbao: Mensajero. 
EGAN, K. (1994). Fantasía e imaginación: su poder en la enseñanza. Madrid: Morata/M.E.C.

ELIADE, M. (1973). Mito y realidad. Madrid: Guadarrama.

ENCABO, E. (2000). La inclusión como referente antinómico de la discriminación: la lectura es para todas las personas. En AA.VV. Lectura y valores II. Badajoz. Servicio de Publicaciones de la Universidad de Extremadura, 56-60.

HELLER, M. F. (1999). Reading-writing connections. From theory to practice. Londres: Lawrence Erlbaum Associates.

JAKOBSON, R. (1984). Ensayos de lingüística general. Barcelona: Ariel.

LÓPEZ, A. (1995). Estrategias didácticas para la producción de textos. En B. MANTECÓN y F. ZARAGOZA (Eds.). La gramática y su didáctica. Málaga: Universidad de Málaga/SEDLL, 218-225.

LÓPEZ, A. y ENCABO, E. (2000a). Tiempos de neoliberalismo, tiempos de incomunicación: la exigencia de enseñar Lengua y Literatura desde un enfoque crítico y reflexivo. Revista Campo Abierto, 17, 63-77.

LÓPEZ, A. y ENCABO, E. (2000b). La función poética o cuando el lenguaje se hace creación. Literatura Infantil y Juvenil, 168, 19-24.

LÓPEZ, A. y ENCABO, E. (2000c). Repensando la competencia literaria: hacia una orientación axiológica. Puertas a la lectura, 9-10, 89-94.

LÓPEZ, A. y ENCABO, E. (2000d). El taller de creación literaria como iniciación a la Literatura Infantil y Juvenil. En A. SUÁREZ y E. MARTOS (Coords.). Identidad cultural del niño, tradiciones y Literatura Infantil. Badajoz: Servicio de Publicaciones de la Diputación Provincial, 103-111.

LÓPEZ, A. y ENCABO, E. (2001a). El aula feliz. Heurística de la comunicación. Barcelona: Octaedro.

LÓPEZ, A. y ENCABO, E. (2001b). Mejorar la comunicación en niños y adolescentes. Madrid: Pirámide.

MARTOS, E. (1988). La poética del patetismo. Mérida: Editora Regional de Extremadura.

MAY, R. (1998). La necesidad del mito. La influencia de los modelos culturales en el mundo contemporáneo. Barcelona: Paidós.

MENDOZA, A., LÓPEZ, A. y MARTOS, E. (1996). Didáctica de la Lengua para la enseñanza primaria y secundaria. Madrid: Akal.

MOORMANN, E. M. y UITTERHOEVE, W. (1997). De Acteón a Zeus. Madrid: Akal.

NOBILE, A. (1992). Literatura Infantil y Juvenil. Madrid: Morata/M.E.C.

OBIOLS, N. (1998). Cómo desarrollar los valores a partir de la Literatura. Barcelona: Ceac.

PARKIN, R. (1998). Antropología simbólica. En C. Lisón (Ed.). Antropología: horizontes teóricos. Granada: Comares, 121-148. 
PROPP, V. (1977). Morfología del cuento. Caracas: Fundamentos.

RAINES, S. e ISBELL, R. (2000). Cómo contar cuentos a los niños: relatos y actividades para estimular la creatividad e inculcar valores éticos. Barcelona: Oniro.

ROWSHAN, A. (1999). Cómo contar cuentos: un método para ayudar al niño a crecer y a resolver sus problemas más habituales. Barcelona: RBA libros.

RODARI, G. (1991). Gramática de la fantasía. Introducción al arte de inventar historias. Barcelona: Aliorna.

SÁNCHEZ, L. (1995a). Literatura Infantil y lenguaje literario. Barcelona: Paidós.

SÁNCHEZ, L. (1995b). El cuento infantil: desde la antropología a la Literatura. En P. Guerrero y A. López (Eds.). Aspectos de Didáctica de la Lengua y la Literatura. Murcia: Servicio de Publicaciones de la Universidad, 793-799.

SOTOMAYOR, Mạ. Vạ. (2000). Lenguaje literario, géneros y literatura infantil. En P. CERRILLO y J. GARCÍA (Coords.). Presente y futuro de la Literatura Infantil. Cuenca: Servicio de Publicaciones de la Universidad de Castilla-La Mancha, 27-65.

TEJERO, E. (1997). El retorno de los mitos. Mitología. Literatura. Transferencia didáctica. Didáctica (Lengua y Literatura), 9, 279-310.

TODOROV, T. (1988). El origen de los géneros. En M. A. Garrido (Comp.). Teoría de los géneros literarios. Madrid Arco libros, 31-48.

TRIGO, J. M. y otros (1997). El niño de hoy ante el cuento. Sevilla: Guadalmena.

VAN GENNEP, A. (1982). La formación de las Leyendas. Barcelona: Alta Fulla.

ZARO, J. J. y SALABERRI, S. (1993). Contando cuentos. Edinburgh: Heinemann. 